\title{
Effects of Oil and Gas Production on Lake Meredith Sediments, 1964-99
}

Lake Meredith lies on the dry and windswept High Plains of the Texas Panhandle and is a popular recreation area for the region. Oil and gas exploration and extraction have been ongoing at Lake Meredith National Recreation Area since about 1930. More than 250 wells, including those abandoned or relocated, are within the boundaries of the recreation area. Oil and gas wells in the watershed of Lake Meredith number in the thousands.

Many contaminants are associated with oil and gas operations. Some of the contaminants can persist for decades in the environment. Trace elements and hydrocarbons are the principal contaminants associated with drilling muds, produced

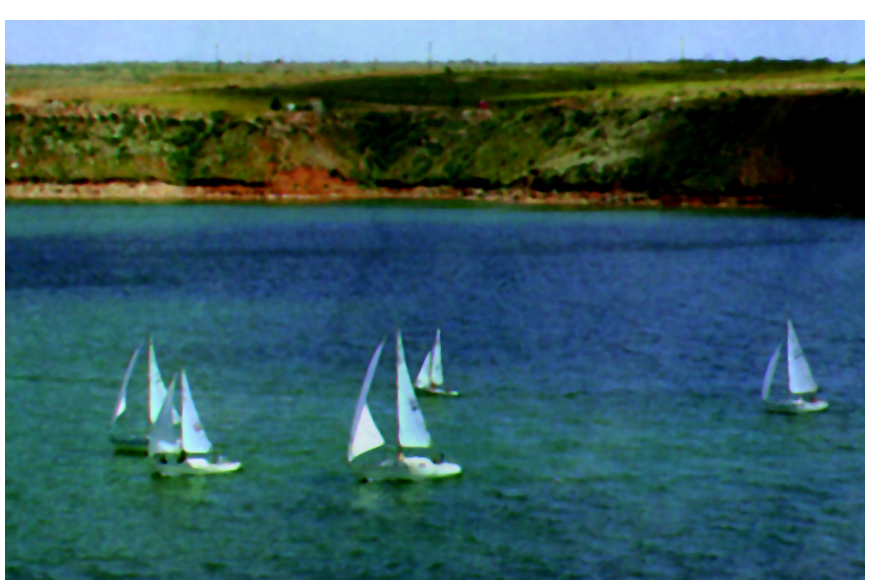
\begin{abstract}
water, and crude oil. These elements and compounds include barium, cadmium, chromium, lead, mercury, nickel, strontium, zinc, sodium, polycyclic aromatic hydrocarbons (PAHs), benzene, ethylbenzene, toluene, and xylene.

Because many of the contaminants associated with oil and gas production are hydrophobic (that is, they adsorb preferentially to soil and sediment), the erosion and transport of contaminated soil particles could cause contaminants to move into the lake. High concentrations of contaminants such as PAHs and heavy metals on sediment could have an adverse effect on aquatic life including microinvertebrates, macroinvertebrates, freshwater mussels, and fish.
\end{abstract}

A study was conducted in 1999 to determine the effects of historical oil and gas production on the bottom-sediment chemistry of the lake. The study was part of the Water Quality Partnership Program between the U.S. Geological Survey (USGS) and the National Park Service. The study sought to answer three questions:

\section{- Are oil and gas operations having a discernible effect on sediment quality in the lake?}

\section{- How have concentrations of incoming hydrophobic contaminants changed over the years?}

\section{- Are current concentrations of hydrophobic contaminants in bottom sediments at levels of concern for the health of aquatic biota?}

\section{To answer these questions, sediment cores were collected from two sites in the lake. Sediment cores can be used to reconstruct historical trends in hydrophobic contaminants (Eisenreich and others, 1989; \\ Van Metre and others, 1997, 2000). In addition, surficial bottom sediments were collected from six sites at the mouths of inflowing streams. Samples from the cores and of surficial bottom sediments were analyzed for major and trace elements, PAHs and biomarkers such as pristane and phytane, and organochlorine compounds. This fact sheet describes the methods and documents the results of the study.}

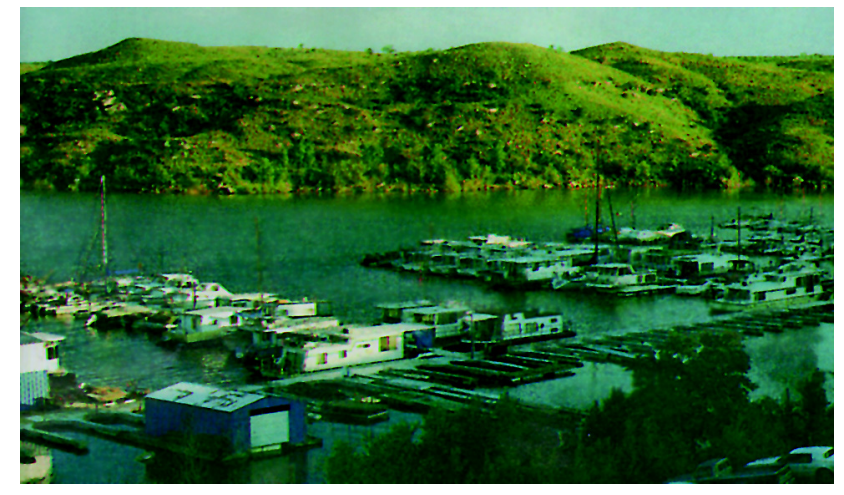




\section{How We Sample}

Two basic types of coring tools were used: a cylindrical piston corer and a box corer. The piston corer collects relatively long (as much as 3.5 meters [m]), 6 -centimeter $(\mathrm{cm})$ diameter tubes of mud. The box corer collects a sample as thick as $20 \mathrm{~cm}$ and $14-\mathrm{cm}$ square and has jaws that close at the bottom to hold the sample. The Lake Meredith cores were collected from a boat. After collection, the core is subsampled by pushing the sediment up through the plastic liner and slicing thin layers of sediment off the top (see photograph below). The chemistry of the samples is measured using various analytical methods. Cesium-137 $\left({ }^{137} \mathrm{Cs}\right)$ is measured by radioactive counting (Van Metre and others, 1998). Major and trace elements are analyzed by inductively-coupled plasma/atomic emission spectroscopy and graphitefurnace atomic adsorption (Fishman and Friedman, 1989). Organic compounds are analyzed by gas chromatography/mass spectrometry (Foreman and others, 1995; Furlong and others, 1996). Ages of sediment layers in the core were assigned on the basis of the ${ }^{137} \mathrm{Cs}$ profile and core lithology similar to the approach used by Van Metre and others (1997), as described at the right.

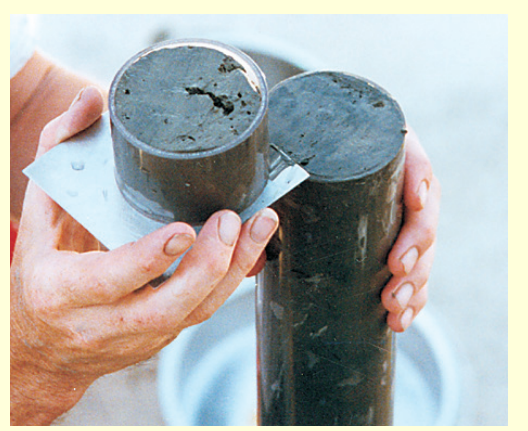

Slicing a subsample from a core for laboratory analysis.

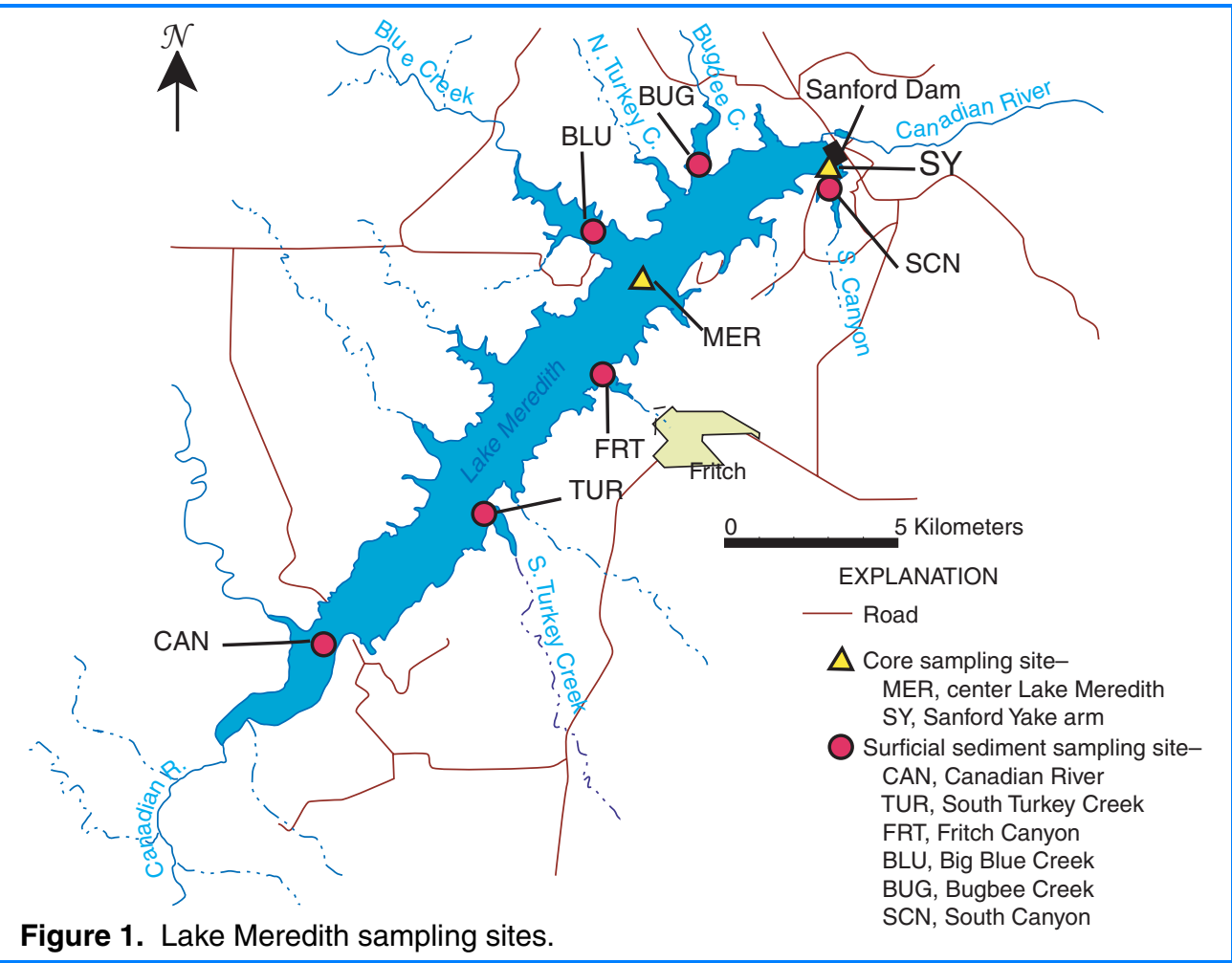

\section{Sample Collection and Age-Dating of Sediment Cores}

Two cores were collected: one from the center of Lake Meredith (MER) and one from the South Canyon or Sanford Yake arm (SY) of the reservoir (fig. 1). A piston corer was used to minimize compression. The MER core was assumed to be representative of sediments throughout the main part of the lake and was subsampled more extensively than the SY core. The SY core was collected to determine if activities in the marina, located in the Sanford Yake arm, or oil and gas production in that area might be contributing to sediment contamination.

Six samples of surficial sediment were collected using a box corer (fig. 1). The samples were collected from the reservoir near the mouth of the Canadian River and five tributaries. At each site, the sample was collected as far up into the arm of the lake as the water depth would allow to ensure that the sediment collected was that contributed by the stream flowing into the lake. The top $3 \mathrm{~cm}$ of sediment from each box core was removed, homogenized, and retained for analysis.

Sediment cores were age-dated by assuming that the depth of the pre-reservoir interface corresponds to 1964, the year the reservoir was built. The pre-reservoir interface was determined on the basis of lithology. The pre-reservoir material contains sand, whereas the reservoir sediment is a chocolate-brown to black clay. Reservoir sediments were $73 \mathrm{~cm}$ thick in the MER core and $110 \mathrm{~cm}$ thick in the SY core. Subsamples were weighed before and after drying to determine porosity and mass. Dates for each depth were assigned on the basis of the assumption that the average mass accumulation per year (MAR) was constant since reservoir construction. MAR at the MER site was 1.1 grams per square centimeter per year $\left(\mathrm{g} / \mathrm{cm}^{2}-\mathrm{yr}\right)$, or about 2.1 centimeters per year $(\mathrm{cm} / \mathrm{yr})$, and at the $S Y$ site was $1.7 \mathrm{~g} / \mathrm{cm}^{2} / \mathrm{yr}$, or about $3.1 \mathrm{~cm} / \mathrm{yr}$, fairly rapid sedimentation rates. Because sedimentation rates probably vary from year to year, the dates assigned are considered estimates. Cesium-137 concentrations were highest at the bottom of the cores and then steadily decreased, which is consistent with date estimates and the assumption that sediment was not resuspended; thus, trends of other constituents can be analyzed with some confidence. 


\section{Trace Elements}

Sediments along the length of the two cores and from the six surficial samples were analyzed for major and minor elements. The results for six of the elements associated with oil and gas production are shown in figure 2 .

Concentrations of most trace elements increase throughout the lower part of the MER core from the time the reservoir was built until about the early 1970s. In general, the contribution of bank erosion to reservoir sediments is greatest during the early history of a reservoir, then decreases as the banks stabilize (Callender and Robbins, 1993). Thus the increase in trace element concentrations in the MER core likely reflects a transition from a mix of local erosion and riverine sources of sediment to sediments originating largely from the Canadian River. This hypothesis is supported by the similarity of concentrations in the MER core to concentrations in the CAN sample since about 1970, assuming that the CAN sample collected in 1999 is representative of historical concentrations of trace elements in the Canadian River.

Overall, sediment quality, as represented by trace elements, does not appear to be affected by oil and gas production around the lake. Concentrations of trace elements in the surficial sediments, with the exception of chromium, nickel, and zinc in the CAN sample, tend to be lower than those in the cores. This could be a grain-size effect. Sediments near the tributary inflows probably contain more sand than the finer grained sediments in the middle of the lake, and trace element concentrations tend to decrease as grain size increases (Horowitz, 1991).

In contrast to the other elements, trends in cadmium concentrations in both cores indicate that cadmium inputs to Lake Meredith were about twice as high in the 1970s and 1980s as they are now. The source of the cadmium is not known; however, cadmium concentrations in surficial samples at the mouths of Big Blue Creek (BLU) and Fritch Canyon (FRT) are higher than those at the mouths of the other tributaries, including the Canadian River. It is possible that activities in the watersheds of these two tributaries contributed to the higher concentrations of cadmium being deposited in Lake Meredith 20 to 30 years ago, although it is unlikely that they would affect concentrations in the Sanford Yake arm. Cadmium and other element concentrations are below levels thought to adversely affect biota (MacDonald and others, 2000).

\section{Polycyclic Aromatic Hydrocarbons and Other Petroleum Biomarkers}

PAHs are a large class of compounds made up of combinations of benzene rings. They are present in petroleum, oil, coal, wood, and their combustion products. Their presence in the environment in areas of oil and gas production can be a result of natural seepage or spills and leakage
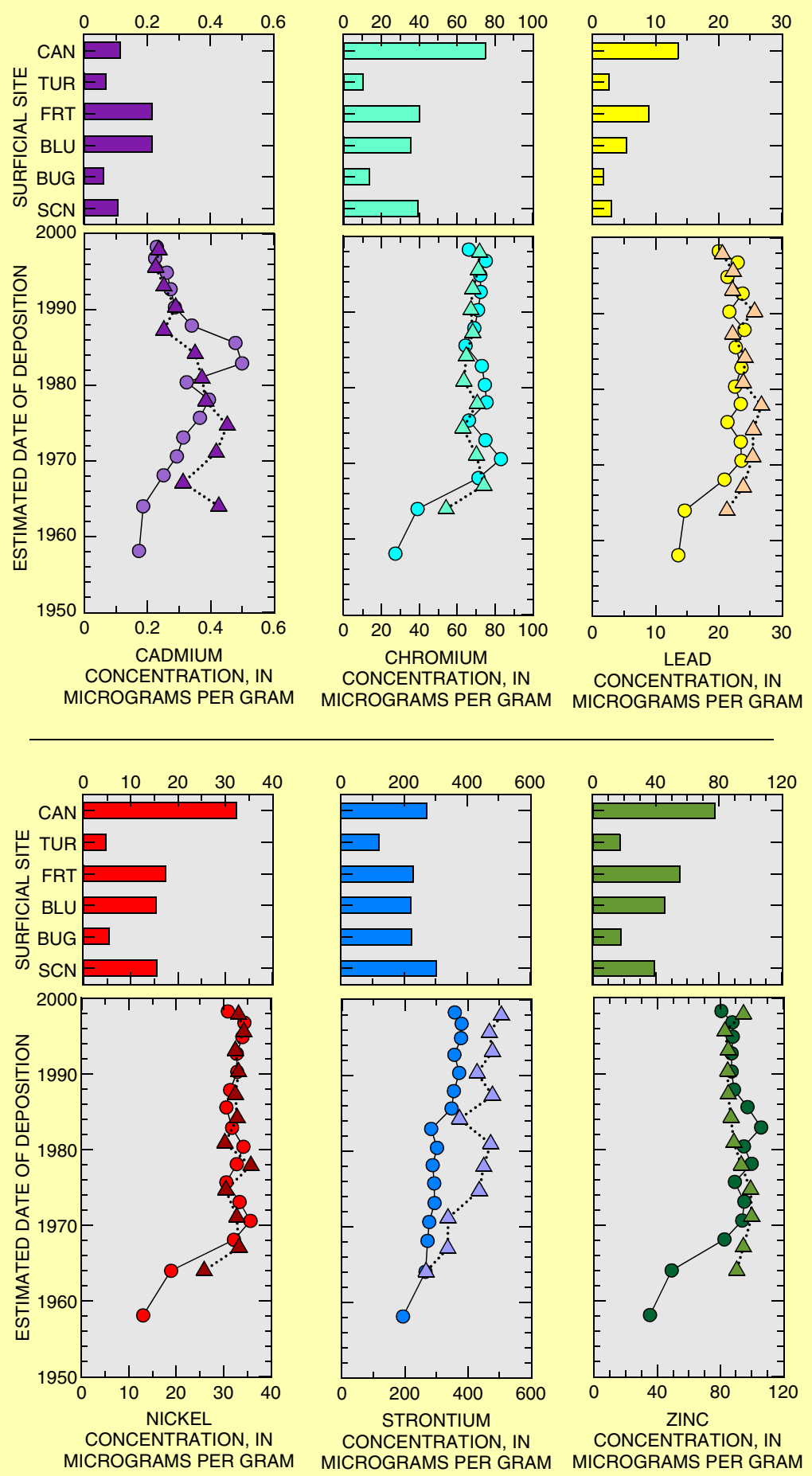

Figure 2. Concentrations of trace elements in surficial sediments and cores. MER core samples are shown by circles, and SY core samples by triangles. 
during transport and production of fossil fuels (Youngblood and Blumer, 1975; Eganhouse and Gossett, 1991). PAHs also have many other anthropogenic sources including vehicles, motor boats, heating and power plants, industrial processes, and refuse and open burning (Sims and Overcash, 1983) and are often found in high concentrations in urban areas (Van Metre and others, 2000). They are of concern in the environment because they represent the largest class of suspected carcinogens (Björseth and Ramdahl, 1985).

Concentrations of total PAHs (the sum of 19 parent PAHs, 10 specific alkyl-PAHs, and the homologous series of alkyl-PAHs) in cores and surficial sediments from Lake Meredith were very low (fig. 3). The highest concentration detected was less than 800 micrograms per kilogram $(\mu \mathrm{g} / \mathrm{kg})$, and the median concentration was 60 $\mu \mathrm{g} / \mathrm{kg}$. These concentrations are within the range of concentrations in soils and sediments that are considered uncontaminated (Youngblood and Blumer, 1975). Furthermore, concentrations less than about $1,600 \mu \mathrm{g} / \mathrm{kg}$ are believed to have no adverse effects on aquatic biota (MacDonald and others, 2000).

Although concentrations of total PAHs are low, some indications of trend and source can be seen in the cores and surface samples. Concentrations in the MER core are very low (less than $100 \mu \mathrm{g} / \mathrm{kg}$ ) and show no trend, whereas concentrations in the lower part of the SY core are about three times higher, then decrease at the top of the core to concentrations similar to those in the MER core. Although the number of datapoints is small, the trend suggests that some activities in the surrounding watershed in the 1970s and 1980s contributed PAHs to the sediments but that those activities have largely ceased. The concentration of total PAHs in the sample from the Fritch Canyon (FRT) site, at the mouth of the creek whose watershed includes the town of Fritch, is higher than that at any of the other surface sites or in either of the cores. Although the concentration is low, its magnitude in relation to the others suggests that this small urbanized area of the Lake Meredith watershed contributes a relatively greater amount of PAHs than oil and gas production in the remainder of the watershed.

Information also can be obtained by looking at the assemblage of PAHs present. Uncombusted sources (for example, oil seeps or petroleum spills) are made up mostly of 2- and 3-ringed PAHs, whereas combustion (for example, vehicle exhaust, domestic heating with coal, and many industrial processes) produces mostly 4- and 5-ringed PAHs. The ratio of the sum of the 2- and 3-ringed PAHs to the sum of the combustion products is an indication of the PAH source: A decrease in this ratio indicates a shift from uncombusted to combusted fossil fuels as the PAH source. Trends in this ratio in the core from the main lake (MER) indicate that uncombusted fossil fuels might have been more of a factor than combustion products early in the reservoir history. In the samples of surficial lake sediments, this ratio is much lower at the FRT site than at the other sites. Lower ratios are typical of urbanization (Van Metre and others, 2000). The $\mathrm{PAH}$ ratio at this site is consistent with the hypothesis that sediments from Fritch Canyon are affected by PAHs resulting from urban activities in the town of Fritch.

Ratios of other petroleum biomarkers also can be used to infer sources of natural and pollutant hydrocarbons in sediments. Among these is the ratio of pristane to phytane, two isoprenoid alkanes present in most petroleum (Volkman and others, 1997). This ratio usually is an indication of the oxidation-reduction conditions in the environment where the petroleum was first formed and thus acts as a "signature" for a particular source of petroleum. The pristane/phytane ratio in the MER core is much more variable than that in the SY core (fig. 3). This result supports the hypothesis that a shift in the source of petroleum or petroleum-product inputs to the lake, represented by the MER site, might have occurred after the reservoir was built, but that inputs to the SY site were more uniform. 


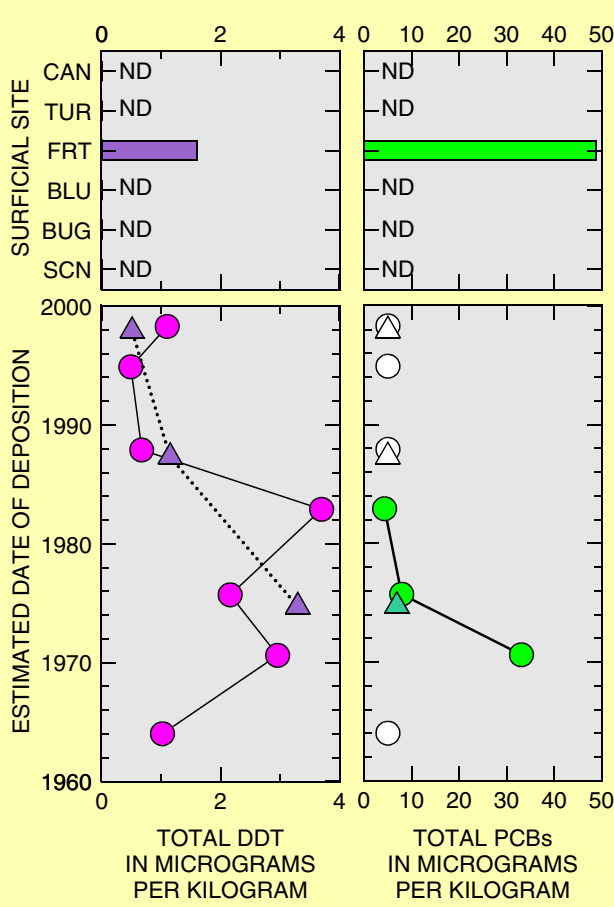

Figure 4. Concentrations of total DDT and total PCBs in surficial sediments and cores. MER core samples are shown by circles, and SY core samples by triangles. Non-detections are indicated by ND or white symbols.

\section{Organochlorine Compounds}

Although organochlorine compounds are not products of the oil and gas industry, concentrations of selected organochlorine compounds were analyzed in the cores and surficial lake sediments to determine if agricultural or industrial activities have had a measurable effect on lake sediment quality since the construction of the reservoir. Many organochlorine compounds, such as chlordane, DDT, and polychlorinated biphenyls (PCBs), have been banned, but because of their chemical persistence they can occur in soils for decades after their application. Chlordane, an organochlorine pesticide banned in 1988, was not detected in any samples, at a reporting level of $5.0 \mu \mathrm{g} / \mathrm{kg}$. DDT (expressed here as total DDT, the sum of DDT and its two breakdown products DDD and DDE), however, was detected along the entire length of both cores as well as in the sediment from the mouth of Fritch Canyon (fig. 4). In sediment cores from 10 other reservoirs across the United States, concentrations of DDT peak in the 1960s before it was banned in 1972 (Van Metre and others, 1997, 1998). The detection of DDT in the sample from the mouth of Fritch Canyon suggests that historical urban uses in Fritch could be a source of DDT to the lake.

PCBs, a group of industrial organochlorine compounds, were detected in sediments from Lake Meredith. PCBs had many industrial and commercial uses, primarily as a lubri- cant in pumps, or as insulation fluids for transformers and appliances, and were widely used before their ban in 1971 . The decreasing trend seen in the MER core are similar to those seen in sediment cores from reservoirs across the country (Van Metre and others, 1997, 1998). PCBs were not detected in either the MER or SY core in sediments deposited after about the early 1980s. PCBs were, however, detected in the sample of sediment collected from the mouth of Fritch Canyon. The concentration, $49 \mu \mathrm{g} / \mathrm{kg}$, was higher than any of the concentrations in the cores, including those in sediments deposited during the height of PCB use. This concentration, although high relative to the other detections, is less than the concentration below which PCBs are thought to have no adverse effect on the health of aquatic biota (MacDonald and others, 2000).

\section{Conclusions and Implications}

The many decades of oil and gas exploration and extraction at the Lake Meredith National Recreation Area seem to have had little effect on sediment quality in Lake Meredith. The relatively low concentrations of all contaminants compared to concentrations in urban lakes (Van Metre and others, 1997, 2000) and to sediment-quality guidelines (MacDonald and others, 2000) could be a result of dilution by the large amount of sediment being deposited in the lake from undeveloped areas in the watersheds of the Canadian River and its tributaries. Average sedimentation rates in the MER and SY cores were estimated to be 2.1 and $3.1 \mathrm{~cm} / \mathrm{yr}$, respectively.

The importance of incoming sediment from the Canadian River is reflected in the composition of trace elements in contemporary reservoir sediments. The relative concentrations of trace elements have a signature reflecting sediment mostly from the Canadian River as opposed to sediments from the smaller tributaries. Trace elements associated with drilling muds, produced water, and crude oil all occur in lake sediments at concentrations below those thought to have a probable effect on the health of aquatic biota (MacDonald and others, 2000).

Concentrations of total PAHs, another contaminant associated with oil and gas production, are very low in all samples, similar to those in undeveloped settings and well below the concentration defining the threshold below which PAHs are thought to have no adverse effects on the health of aquatic biota (MacDonald, 2000). Trends in both the ratios of indicator PAHs and petroleum biomarkers suggest that the principal source of incoming PAHs might have changed from uncombusted fossil fuels (for example, crude and refined petroleum) to combusted fossil fuels (for example, vehicle and motor boat emissions) since the construction of the lake.

Activities other than oil and gas production in the Lake Meredith watershed have left their mark in the sediments 
deposited in the lake. Profiles of DDT and PCBs in sediment cores are evidence of use of these compounds through the 1960s, followed by a decrease in or cessation of their use after they were banned. DDT is still detectable in the most recently deposited sediments, although PCBs are not.

The samples collected at the mouths of the tributaries tell perhaps the most interesting story about the effects of different types of land use on sediment quality. Of the samples collected at the mouth of the Canadian River and five tributaries, the one that stands out was collected at the mouth of Fritch Canyon. Within the watershed of this small tributary is the town of Fritch (population about 2,000), the only "urban" development in the vicinity of Lake Meredith. Both DDT and PCBs, undetected at the other five tributary sites, were detected at this site, and concentrations of PAHs were more than seven times those detected at any of the other sites. Although these concentrations are low relative to those from truly urban settings, the difference in concentrations between this site and others suggests that Lake Meredith residential and commercial land use could be having a greater effect on sediment quality than oil and gas exploration and extraction.

\section{References}

Bjõrseth, A., and Ramdahl, T., 1985, eds., Handbook of polycyclic aromatic hydrocarbons-v. 2, Emission sources and recent progress in analytical chemistry: New York, Marcel Dekker Inc., $432 \mathrm{p}$.

Callender, Edward, and Robbins, J.A., 1993, Transport and accumulation of radionuclides and stable elements in a Missouri River reservoir: Water Resources Research, v. 29 , p. 1,787-1,804.

Eganhouse, R.P., and Gossett, R.W., 1991, Historical deposition and biogeochemical fate of polycyclic aromatic hydrocarbons in sediments near a major submarine wastewater outfall in southern California, in Baker, R.A., ed., Organic substances and sediment in water: Boca Raton, Fla., Lewis Publishers, p. 191-220.

Eisenreich, S.J., Capel, P.D., Robbins, J.A., and Boubonniere, R., 1989, Accumulation and diagenesis of chlorinated hydrocarbons in lacustrine sediments: Environmental Science and Technology, v. 23, no. 9, p. 1,116-1,126.

Fishman, M.J., and Friedman, L.C., eds., 1989, Methods for determination of inorganic substances in water and fluvial sediments: U.S. Geological Survey Techniques of WaterResources Investigations, book 5, chap. A1, 545 p.

Foreman, W.T., Connor, B.G., Furlong, E.T., Vaught, D.G., and Merten, L.M., 1995, Methods of analysis by the U.S. Geological Survey National Water Quality Laboratory-Determination of organochlorine pesticides and polychlorinated biphenyls in bottom sediment by dual capillary-column gas chromatography with electron-capture detection: U.S. Geological Survey Open-File Report 94-140, 78 p.

Furlong, E.T., Vaught, D.G., Merten, L.M., Foreman, W.T., and Gates, P.M., 1996, Methods of analysis by the U.S. Geological Survey National Water Quality Laboratory-Determination of semivolatile organic compounds in bottom sediment by solvent extraction, gel permeation chromatographic fractionation, and capillary-column chromatography/mass spectrometry: U.S. Geological Survey Open-File Report 95-719, $67 \mathrm{p}$.

Horowitz, A.J., 1991, A primer on sediment-trace element chemistry (2d ed.): Chelsea, Mich., Lewis Publishers, 136 p.

MacDonald, D.D., Ingersoll, C.G., and Berger, T.A., 2000, Development and evaluation of consensus-based quality guidelines for freshwater ecosystems: Archives of Environmental Contamination and Toxicology, v. 39, p. 20-31.

Sims, R.C., and Overcash, W.R., 1983, Fate of polynuclear aromatic compounds (PNAs) in soil-plant systems: Residue Reviews, v. 88,67 p.

Van Metre, P.C., Callender, Edward, and Fuller, C.C., 1997, Historical trends in organochlorine compounds in river basins identified using sediment cores from reservoirs: Environmental Science and Technology, v. 31, no. 8, p. 2,339-2,344.

Van Metre, P.C., Mahler, B.J., and Furlong, E.T., 2000, Urban sprawl leaves its PAH signature: Environmental Science and Technology, v. 34, p. 4,064-4,070.

Van Metre, P.C., Wilson, J.T., Callender, Edward, and Fuller, C.C., 1998, Similar rates of decrease of persistent, hydrophobic and particle-reactive contaminants in riverine systems: Environmental Science and Technology, v. 32, no. 21, p. 3,312-3,317.

Volkman, J.K., Revill, A.T., and Murray, A.P., 1997, Applications of biomarkers for identifying sources of natural and pollutant hydrocarbons in aquatic environments, in Eganhouse, R.P., Molecular markers in environmental chemistry: American Chemical Society, ACS Symposium Series 671, p. 110-132.

Youngblood, W.W., and Blumer, M., 1975, Polycyclic aromatic hydrocarbons in the environment-Homologous series in soils and recent marine sediments: Geochimica et Cosmochimica Acta, v. 39, p. 1,303-1,314.

-B.J. Mahler and P.C. Van Metre

Any use of trade, product, or firm names is for descriptive purposes only and does not imply endorsement by the U.S. Government.

\section{Information on technical reports and hydrologic data related to this study can be obtained from:}

District Chief

U.S. Geological Survey

8027 Exchange Dr.

Austin, TX 78754-4733

E-mail: dc_tx@usgs.gov
Phone: (512) 927-3500

FAX: (512) 927-3590

World Wide Web:

http://tx.usgs.gov/ 